\title{
Physical functioning and perceived health status after surviving the first COVID-19 wave. A long-term observational perspective
}

Francesco Ferrarello ( $\nabla$ francesco.ferrarello@usicentro.toscana.it )

Azienda USL Toscana centro Sedi di Prato https://orcid.org/0000-0001-9404-3068

Carmela lacopino

Azienda USL Toscana centro Sedi di Prato

Catia Pierinelli

Azienda USL Toscana centro Sedi di Prato

\section{Research Article}

Keywords: Coronavirus infections, Disabled persons, Physical therapy modalities, Recovery of function, Perceived health status

Posted Date: April 30th, 2021

DOI: https://doi.org/10.21203/rs.3.rs-421937/v1

License: (c) (i) This work is licensed under a Creative Commons Attribution 4.0 International License. Read Full License 


\section{Abstract}

After the COVID-19 infection, individuals can experience impairment, activity limitation and participation restriction. Little information is available on range and frequency of individual problems arising after COVID-19 and its sequelae and long-term outcomes. In June and July 2020, nineteen individuals previously hospitalized with COVID-19 were referred to our outpatient physiotherapy unit. We monitored their level of independence in activities of daily living, mobility, and perceived health status for 7.4-9.5 months (median, 8.6) after healing. At baseline, our cohort showed substantial independence in activities of daily living, some mobility limitations, and below average perceived health status. Measures improved over time. Limitations of physical functioning were mostly moderate to slight and tending to improve; if present, severe limitations were probably related to pre-COVID-19 conditions. However, individuals in some cases may not have fully recovered their premorbid functioning seven to nine months after healing.

\section{Introduction}

The World Health Organization has declared the COVID-19 pandemic an international health emergency. COVID-19 could cause severe interstitial pneumonia and shows variability in symptoms and disease severity levels [1]. The occurrence of frailty and underlying illnesses may affect clinical presentation and course characteristics of the disease [1, 2]. Health measures adopted to limit the diffusion of the disease (e.g., isolation, quarantine, social distancing, community containment), may contribute to negative health outcomes and disabilities [3].

After the COVID-19 infection, individuals can experience impairment, activity limitation and participation restriction. Impaired physical functioning has been observed at discharge, even after early mobilisation/bedside physiotherapy [4]. Physiotherapists are important across the COVID-19 care continuum [5] and it would be appropriate to offer to this population specific physiotherapy services [6].

Little information is currently available on range and frequency of individual problems arising after COVID-19 and its sequelae and long-term outcomes [7]. Knowledge on functioning of individuals after COVID-19 may help to understand their potential impact on physiotherapy practice and service provision. Our unit provided an outpatient- specific physiotherapy service to individuals who recovered from the disease. Four face-to-face physiotherapy intervention modalities were organized: short- counseling (sessions, 1-3), extended- counseling (sessions, >3), individual intervention (sessions, 10-15), and group intervention (sessions, 10). The actual choice was based on clinical conditions and the needs of individuals and their caregivers; interventions were tailored accordingly.

The purpose of this brief communication is to describe the long-term progression of independence in the basic activities of daily living, mobility, and perceived health status in a cohort of individuals referred to an outpatient functional rehabilitation clinic, after surviving the first COVID-19 wave.

\section{Methods}


A cohort of individuals previously affected by COVID-19 was monitored up to six months after the end of physiotherapy. All the individuals recovering from the first infection wave referred to the local health authority outpatient functional rehabilitation clinic were invited to participate in the study. Data were collected at baseline (T0), at the end of the intervention (T1), and two (T2) and six (T3) months after the end of treatment. Telephone follow-up was eventually proposed if transportation/traveling or other difficulties arose. Individuals were referred in May and July 2020; we performed the last follow-up on March 22, 2021. The local Ethics Committee approved the study, participants given informed consent.

Relevant data were extracted using a standard data recording spreadsheet, including characteristics of the participants (age, number of falls in the last 12 months, comorbidities) and COVID-19-related issues (infection duration, locations of the course of the disease). The Pfeiffer Short Portable Mental Status Questionnaire [8] was used to measure intellectual functioning.

The physical functioning assessment comprised the modified Barthel index (BI) [9], the Timed Up and Go test (TUG) [10], and the Short Physical Performance Battery test (SPPB) [11]. The Patient Specific Functioning Scale (PSFS) [12] was used to measure changes in physical function; individuals were invited to define the most important physical activity with which they were having difficulty, and rate the difficulty using as a reference the level of performance before the COVID-19 infection. The minimal detectable change (MDC) has been estimated in community dwelling adults for the SPPB and PSFS scales [11, 12]. The EuroQOL 5D-3L (index and Visual Analogue Scale-VAS) [13], was adopted as measure of perceived health status.

We used descriptive statistics to depict the characteristics of the participants and COVID-19-related issues. The Friedman test was utilized to assess variations across the assessments; in case of significant results, post-hoc analysis was conducted by the Dunn test, with Bonferroni correction. The significant level was set at $p \leq 0.05$. Analysis was intention-to-treat, missing data were dealt with carrying the last observation forward. We further analysed data on SPPB and PSFS by plotting change scores and the range of random measurement error (i.e., the interval spanning between the \pm MDC values) and computing the proportions (95\% Confidence Interval-Cl) of individuals showing an improvement in performance equal to or greater than the absolute MDC value. Analyses were performed with IBM SPSS Statistics software for Windows (version 20.0; IBM Corp, Armonk, NY).

\section{Results}

Nineteen individuals surviving the first COVID-19 wave accessed our clinic and consented to participate. The participants (male, 8 ) were 35-94 years old (median, 76 year). Time between hospitalization and healing/end of the isolation ranged from 16 to 129 days (median, 44 days). Frequent comorbidities were hypertension, hypercholesterolemia, heart and circulation disorders, and others (e.g., COPD, disorders of the prostate or thyroid glands). When the infection occurred, two individuals were admitted to the hospital for mild or severe stroke, and one for a femur fracture. All had been hospitalized in acute inpatient wards (intensive care unit, 4). Fifteen of them were transferred to low care wards, and four were discharged and 
isolated in non-hospital facilities (COVID-19 hotel, 2; home, 2). The individuals mostly accessed the baseline assessment session walking independently (alone, 9; accompanied, 8); two of them attended the clinic in a wheelchair.

According to the Pfeiffer short portable mental status questionnaire, three individuals had severe impairment, intellectual functioning was otherwise intact. The informed consent was given by the daughters in cases suffering from severe aphasia or intellectual impairment.

Individuals attended $1-15$ sessions (median, 10) in 1-63 days (median. 42), and were monitored for 180-252 days (median, 223). The TUG test was not administered to individuals unable to walk independently and to the 94-year-old lady who reported high perceived exertion at rest (Borg Scale CR10, 7). The EuroQOL was not administered to the individual with severe aphasia. All but one individual were evaluated at T1; a participant felt recovered and withdrew from the intervention after the 3rd session. Two other individuals refused to participate in the T2 and T3 follow-up (did not like to evoke the illness or worsening of health condition). Telephone follow-up (i.e., assessing BI, PSFS, and EuroQOL) was administered to three individuals at T2, and four at T3.

At baseline about half of the individuals were independent in BADL, one quarter showed a slight dependency, whereas the remaining ones presented moderate to total dependency (Fig. 1). TUG and SPPB scores were 7.62-32.33 seconds (median, 12.42) and 0-12 points (median, 8), respectively (Fig. 1). Seven out of 16 individuals were at fall risk (i.e., TUG > 13.5 seconds) [10], and all but two presented mobility disability (i.e., SPPB score $\leq 10$ ) [11]. Individuals mostly reported walking (quality and quantity) as the important activity they were having difficulty with because of their past condition, other activities frequently identified were housekeeping and climbing/descending stairs; PSFS score was 0-7 (median, 4). The EuroQOL-index showed a perceived health status in line with the population norms values (0.18-1.00; median, 0.87), whereas the EuroQOL-VAS scores were slightly below the average (5085; median, 59) [13] (Fig. 1). 
Table 1

Outcome data.

\begin{tabular}{|c|c|c|c|c|c|c|}
\hline Variable & $N$ & TO & $\mathrm{T} 1$ & $\mathrm{~T} 2$ & T3 & $\begin{array}{l}p \\
\text { value }\end{array}$ \\
\hline $\mathrm{BI}$ & 19 & $\begin{array}{l}98(90 \\
\text { to100) }\end{array}$ & $\begin{array}{l}100 \text { (97 to } \\
100)\end{array}$ & $\begin{array}{l}100 \text { (96 to } \\
100)\end{array}$ & $\begin{array}{l}100 \text { (95 to } \\
100)\end{array}$ & $.008^{\mathrm{a}}$ \\
\hline TUG & 16 & $\begin{array}{l}12.43(10.03 \\
\text { to } 16.40)\end{array}$ & $\begin{array}{l}10.66(8.43 \\
\text { to } 14.66)\end{array}$ & $\begin{array}{l}9.81(8.22 \\
\text { to } 15.29)\end{array}$ & $\begin{array}{l}8.99(7.95 \\
\text { to } 13.33)\end{array}$ & $.006^{a}$ \\
\hline At fall risk & & $\begin{array}{l}7(44 \%, 23- \\
67)\end{array}$ & $\begin{array}{l}4(25 \%, 10- \\
49)\end{array}$ & $\begin{array}{l}5(31 \%, \\
14-56)\end{array}$ & $\begin{array}{l}4(25 \% \\
10-49)\end{array}$ & \\
\hline SPPB & 19 & 8 (5 to 9$)$ & $9(6$ to 11$)$ & $\begin{array}{l}11(4 \text { to } \\
12)\end{array}$ & $\begin{array}{l}10(4 \text { to } \\
12)\end{array}$ & $.002^{\mathrm{a}}$ \\
\hline $\begin{array}{l}\text { Mobility } \\
\text { disability }\end{array}$ & & $\begin{array}{l}17(89 \%, 69- \\
97)\end{array}$ & $\begin{array}{l}12(63 \%, \\
41-81)\end{array}$ & $\begin{array}{l}9(47 \%, \\
27-68)\end{array}$ & $\begin{array}{l}11(58 \%, \\
36-77)\end{array}$ & \\
\hline PSFS & 19 & $\begin{array}{l}4.0(3.0 \text { to } \\
6.0)\end{array}$ & $\begin{array}{l}7.0(5.0 \text { to } \\
8.0)\end{array}$ & $\begin{array}{l}7.0(3.0 \text { to } \\
8.0)\end{array}$ & $\begin{array}{l}7.5(5.0 \text { to } \\
8.5)\end{array}$ & $<.001^{\mathrm{a}}$ \\
\hline $\begin{array}{l}\text { EuroQOl } \\
\text { 5D index }\end{array}$ & 17 & $.87(.80-.92)$ & $\begin{array}{l}.90(.80 \text { to } \\
.92)\end{array}$ & $\begin{array}{l}.90(.85 \text { to } \\
1.00)\end{array}$ & $\begin{array}{l}.90(.82 \text { to } \\
1.00)\end{array}$ & $.014^{\mathrm{a}}$ \\
\hline $\begin{array}{l}\text { EuroQOI } \\
\text { 5D VAS }\end{array}$ & 18 & $\begin{array}{l}59.0(50.0 \text { to } \\
70.0)\end{array}$ & $\begin{array}{l}75.0(67.5 \\
\text { to } 80.0)\end{array}$ & $\begin{array}{l}80.0(67.5 \\
\text { to } 85.0)\end{array}$ & $\begin{array}{l}81.5(57.8 \\
\text { to } 90.0)\end{array}$ & $<.001^{\mathrm{a}}$ \\
\hline $\begin{array}{l}\text { POST HOC } \\
\text { b }\end{array}$ & & \multicolumn{2}{|c|}{$\begin{array}{l}\text { Median of the differences } \\
(95 \% \mathrm{Cl})^{c}\end{array}$} & & & \\
\hline TUG & 16 & T3 vs T0 & $\begin{array}{l}-2.37(-3.52 \\
\text { to }-1.90)\end{array}$ & & & $.004^{d}$ \\
\hline SPPB & 19 & T2 vs T0 & $\begin{array}{l}1.50(0.50 \\
\text { to } 2.50)\end{array}$ & & & $.023^{d}$ \\
\hline \multirow[t]{3}{*}{ PSFS } & 19 & T1 vs T0 & $\begin{array}{l}2.0(1.0 \text { to } \\
3.0)\end{array}$ & & & $.050^{d}$ \\
\hline & & T2 vs T0 & $\begin{array}{l}2.0(1.0 \text { to } \\
3.0)\end{array}$ & & & $.012^{d}$ \\
\hline & & T3 vs T0 & $\begin{array}{l}2.3(1.0 \text { to } \\
3.5)\end{array}$ & & & $.002^{d}$ \\
\hline $\begin{array}{l}\text { EuroQOI } \\
\text { 5D VAS }\end{array}$ & 18 & T2 vs T0 & $\begin{array}{l}15.0(9.0 \text { to } \\
24.0)\end{array}$ & & & $.014^{d}$ \\
\hline
\end{tabular}

\footnotetext{
${ }^{a}$ Friedman tests. ${ }^{b}$ Only significant results. ${ }^{c}$ Hodges-Lehmann estimator. ${ }^{d}$ Dunn tests with Bonferroni correction. Data are absolute frequencies, or median (1st to 3 rd quartile), or absolute frequencies (relative frequencies, 95\% confidence interval). Abbreviations: $\mathrm{BI}=$ Barthel Index; PSFS = Patient Specific Functioning Scale; SPPB = Short Physical Performance Battery test; TUG = Timed Up and Go test; VAS = Visual Analogue Scale.
} 


\begin{tabular}{|c|c|c|c|c|c|c|}
\hline Variable & $N$ & T0 & $\mathrm{T} 1$ & $\mathrm{~T} 2$ & T3 & $\begin{array}{l}p \\
\text { value }\end{array}$ \\
\hline & & T3 vs T0 & $\begin{array}{l}15.0 \text { (7.5 to } \\
23.0)\end{array}$ & & & $.002^{\mathrm{d}}$ \\
\hline \multicolumn{7}{|c|}{$\begin{array}{l}\text { a Friedman tests. }{ }^{b} \text { Only significant results. }{ }^{c} \text { Hodges-Lehmann estimator. }{ }^{d} \text { Dunn tests with Bonferroni } \\
\text { correction. Data are absolute frequencies, or median (1 st to 3rd quartile), or absolute frequencies } \\
\text { (relative frequencies, } 95 \% \text { confidence interval). Abbreviations: BI = Barthel Index; PSFS = Patient } \\
\text { Specific Functioning Scale; SPPB = Short Physical Performance Battery test; TUG = Timed Up and Go } \\
\text { test; VAS = Visual Analogue Scale. }\end{array}$} \\
\hline
\end{tabular}

T0, T1, T2, and T3 assessments were performed 1-83 (median, 28.5), 40-106 (median, 77.5), 103-170 (median, 140), and 222-286 (median, 255) days after end of the isolation, respectively. According to intention-to-treat analysis, Friedman tests showed positive differences between the assessments (Table 1). Post-hoc analysis did not show differences among assessments in BI and EuroQOL-index; positive differences were evident for the TUG (T3 vs T0), SPPB (T2 vs T0), PSFS (T1, T2, and T3 vs T0), and EuroQOL-VAS (T2 and T3 vs T0) values (Table 1).

We observed variations in performance greater or smaller than the absolute MDC value. Compared to baseline SPPB values, five $(26 \%, 95 \% \mathrm{Cl} 12-49)$, ten $(53 \%, 95 \% \mathrm{Cl} 32-73)$, and seven $(37 \%, 95 \% \mathrm{Cl} 19-59)$ individuals showed an improvement greater than the absolute MDC value at $\mathrm{T} 1, \mathrm{~T} 2$, and $\mathrm{T} 3$, respectively, whereas one individual $(5 \%, 95 \% \mathrm{Cl} 1-25)$ showed worsening at $\mathrm{T} 2$ and T3. Compared to baseline PSFS values, six $(32 \%, 95 \% \mathrm{Cl} 15-54)$, five $(26 \%, 95 \% \mathrm{Cl} 12-49)$, and eight $(43 \%, 95 \% \mathrm{Cl} 42-64)$ individuals showed improvement at $\mathrm{T} 1, \mathrm{~T} 2$, and $\mathrm{T} 3$, respectively, whereas one individual $(5 \%, 95 \% \mathrm{Cl} 1-25)$ showed worsening at T2 (Fig. 2).

\section{Discussion}

This brief communication describes the physical functioning and perceived health status of individuals after COVID-19. We prospectively observed our cohort for 7.4-9.5 months after the end of the infection. Our cohort showed substantial independence in activities of daily living. Some mobility limitations were present. Compared to normative data for community dwelling adults, the TUG and SPPB scores were slightly worse [14, 15]. At baseline, many individuals showed disability [11], and, as outlined by the PSFS, walking was an important activity with which they were having difficulty. The EuroQOL-VAS baseline values showed a perceived health status below the average [13]. According to repeated measures statistics, all outcomes increased (Table 1). Post hoc tests did not show differences between assessments of $\mathrm{BI}$ and EuroQOL-index; it is likely due to the prevalence of high scores at baseline, with little chance for subsequent improvement. Mobility measures have improved and the proportion of individuals at fall risk and with mobility disability decreased over time; unlike the TUG values, SPPB scores at T3 did not differ from the T0 ones (Table 1). The PSFS follow-up scores were greater than the baseline ones, as well as the EuroQOL-VAS T2 and T3 values. The analysis of individual data based on MDC displayed low to medium proportions of individuals (26-53\%) showing improvements in SPPB and 
PSFS; two participants experienced worsening beyond the MDC negative value in SPPB and PSFS, respectively. Severe limitations in physical functioning were probably related to pre-COVID-19 conditions, (e.g., a stroke event).

Compared to individuals surviving the first COVID-19 wave at discharge from acute inpatient ward [4] or at admission for inpatient rehabilitation [16] our cohort showed better independence in activities of daily living and mobility performances (i.e., BI and SPPB scores). Data on perceived health status are quite like those reported from others $[17,18]$. High percentages of individuals feeling not fully recovered seven months after the infection have been reported [19].

Our report is limited to a small sample observed in a single-centred study; however, to date, there is not much data available on range and frequency of sequelae and long-term outcomes after COVID-19. It should be considered that participants received attention from physiotherapists; moreover, assessors were not blinded, and some data were missed. We acknowledge that the generalizability of the findings is limited.

\section{Conclusions}

Despite good independence in activities of daily living and perceived health status, individuals hospitalized with first wave COVID-19 in some cases may not have fully recovered their premorbid functioning status seven to nine months after healing. Physiotherapists can play an important role in the knowledge of the functioning of individuals after COVID-19. Observational studies should be designed to eventually confirm our findings, and to research which prognostic factors may impact long-term physical functioning and perceived health status after COVID-19.

\section{Declarations}

Acknowledgements. Not applicable.

Funding. This research did not receive any specific grant from funding agencies in the public, commercial, or not-for-profit sectors.

Conflicts of interest/Competing interests. Authors disclose any financial and personal relationships with other people or organizations that could inappropriately influence (bias) their work.

Ethics approval. The Comitato Etico Regionale per la Sperimentazione Clinica della Regione Toscana authorized the conduction of the study (Sezione: AREA VASTA CENTRO. Register number: 17260_OSS).

Consent to participate. Participant signed the informed consent to participate in the study.

Consent for publication. Not applicable. 
Availability of data and material. The datasets analysed during the current study are available from the corresponding author on reasonable request.

Code availability. Not applicable.

Author contributions. FF, Cl, and CP: conception and design of the study. $\mathrm{FF}$ and $\mathrm{Cl}$ : acquisition and analysis of data. $\mathrm{FF}, \mathrm{Cl}$, and $\mathrm{CP}$ : interpretation of data, drafting and revising the manuscript, final approval of the version to be submitted.

\section{References}

1. Chen J, Qi T, Liu L, Ling Y, Qian Z, Li T, Li F, Xu Q, Zhang Y, Xu S, Song Z, Zeng Y, Shen Y, Shi Y, Zhu T, Lu H. Clinical progression of patients with COVID-19 in Shanghai, China. J Infect. 2020;80(5):e1-e6.

2. Hewitt J, Carter B, Vilches-Moraga A, Quinn TJ, Braude P, Verduri A, Pearce L, Stechman M, Short R, Price A, Collins JT, Bruce E, Einarsson A, Rickard F, Mitchell E, Holloway M, Hesford J, Barlow-Pay F, Clini E, Myint PK, Moug SJ, McCarthy K; COPE Study Collaborators. The effect of frailty on survival in patients with COVID-19 (COPE): a multicentre, European, observational cohort study. Lancet Public Health. 2020;5(8):e444-e451.

3. Moro T, Paoli A. When COVID-19 affects muscle: effects of quarantine in older adults. Eur J Transl Myol. 2020;30:219-222

4. Belli S, Balbi B, Prince I, Cattaneo D, Masocco F, Zaccaria S, Bertalli L, Cattini F, Lomazzo A, Dal Negro F, Giardini M, Franssen FME, Janssen DJA, Spruit MA. Low physical functioning and impaired performance of activities of daily life in COVID-19 patients who survived hospitalisation. Eur Respir J. 2020;56(4):2002096. doi: 10.1183/13993003.02096-2020

5. Dean E, Jones A, Yu HP, Gosselink R, Skinner M. Translating COVID-19 Evidence to Maximize Physical Therapists' Impact and Public Health Response. Phys Ther. 2020;100(9):1458-1464.

6. Falvey JR, Krafft C, Kornetti D. The Essential Role of Home- and Community-Based Physical Therapists During the COVID-19 Pandemic. Phys Ther. 2020;100(7):1058-1061.

7. Wade DT. Rehabilitation after COVID-19: an evidence-based approach. Clin Med (Lond). 2020;20:359365.

8. Pfeiffer E. A short portable mental status questionnaire for the assessment of organic brain deficit in elderly patients. J Am Geriatr Soc. 1975;23:433-441.

9. Shah S, Vanclay F, Cooper B. Improving the sensitivity of the Barthel Index for stroke rehabilitation. J Clin Epidemiol. 1989;42:703-709.

10. Shumway-Cook A, Brauer S, Woollacott M. Predicting the probability for falls in community-dwelling older adults using the Timed Up \& Go Test. Phys Ther. 2000;80:896-903.

11. Vasunilashorn S, Coppin AK, Patel KV, et al. Use of the Short Physical Performance Battery Score to predict loss of ability to walk 400 meters: analysis from the InCHIANTI study. J Gerontol A Biol Sci Med Sci. 2009;64:223-229. 
12. Mathis RA, Taylor JD, Odom BH, Lairamore C. Reliability and Validity of the Patient-Specific Functional Scale in Community-Dwelling Older Adults. J Geriatr Phys Ther. 2019;42(3):E67-E72.

13. Szende A, Janssen B, Cabases J. Self-reported population health: an international perspective based on EQ-5D. Dordrecht: Springer; 2014.

14. Steffen TM, Hacker TA, Mollinger L. Age- and gender-related test performance in community-dwelling elderly people: Six-Minute Walk Test, Berg Balance Scale, Timed Up \& Go Test, and gait speeds. Phys Ther. 2002;82:128-137.

15. Perera S, Mody SH, Woodman RC, Studenski SA. Meaningful change and responsiveness in common physical performance measures in older adults. J Am Geriatr Soc. 2006;54:743-749.

16. Zampogna E, Migliori GB, Centis R, Cherubino F, Facchetti C, Feci D, Palmiotto G, Pignatti P, Saderi L, Sotgiu G, Spanevello A, Zappa M, Visca D. Functional impairment during post-acute COVID-19 phase: Preliminary finding in 56 patients. 2021 Jan 6:S2531-0437(20)30268-3. doi:

10.1016/j.pulmoe.2020.12.008

17. Garratt AM, Ghanima W, Einvik G, Stavem K. Quality of life after COVID-19 without hospitalisation: Good overall, but reduced in some dimensions. J Infect. 2021 Jan 9:S0163-4453(21)00006-2. doi: 10.1016/j.jinf.2021.01.002

18. Garrigues E, Janvier P, Kherabi Y, Le Bot A, Hamon A, Gouze H, Doucet L, Berkani S, Oliosi E, Mallart E, Corre F, Zarrouk V, Moyer JD, Galy A, Honsel V, Fantin B, Nguyen Y. Post-discharge persistent symptoms and health-related quality of life after hospitalization for COVID-19. J Infect. 2020;81(6):e4-e6.

19. Torjesen I. Covid-19: Middle aged women face greater risk of debilitating long term symptoms. BMJ. 2021 Mar 25;372:n829. doi: 10.1136/bmj.n829. PMID: 33766927

\section{Figures}


A

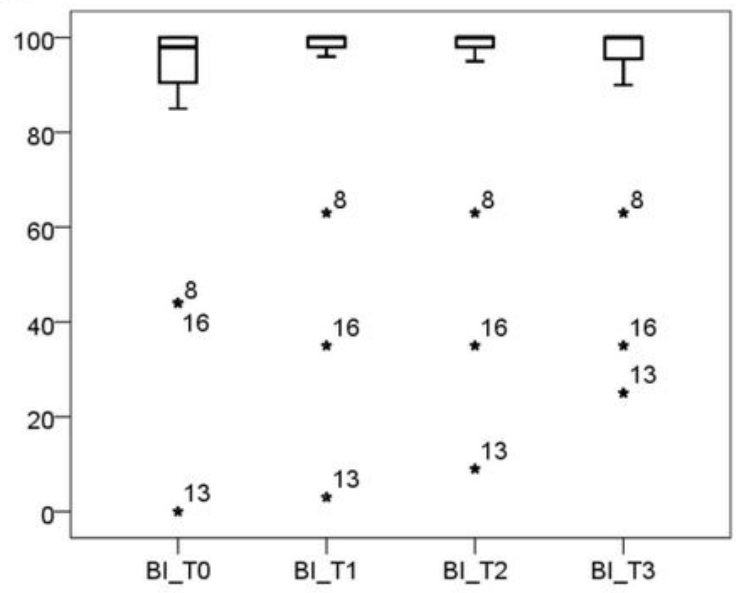

C

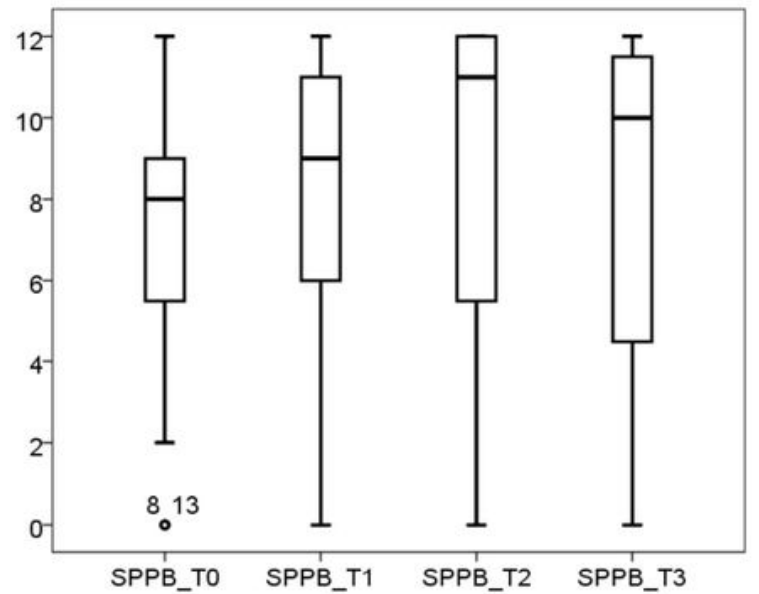

E

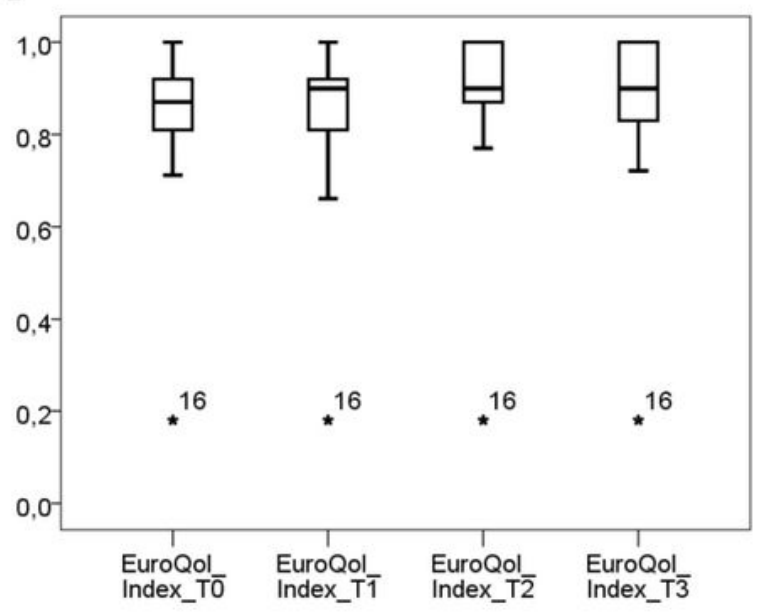

B

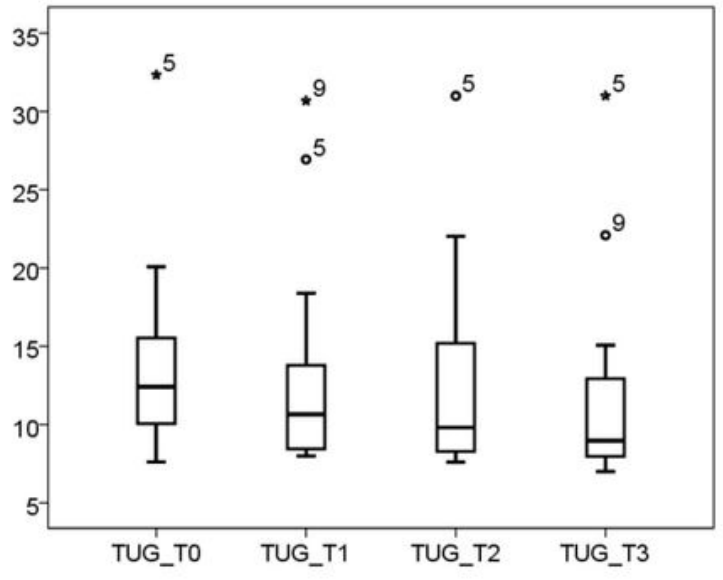

D

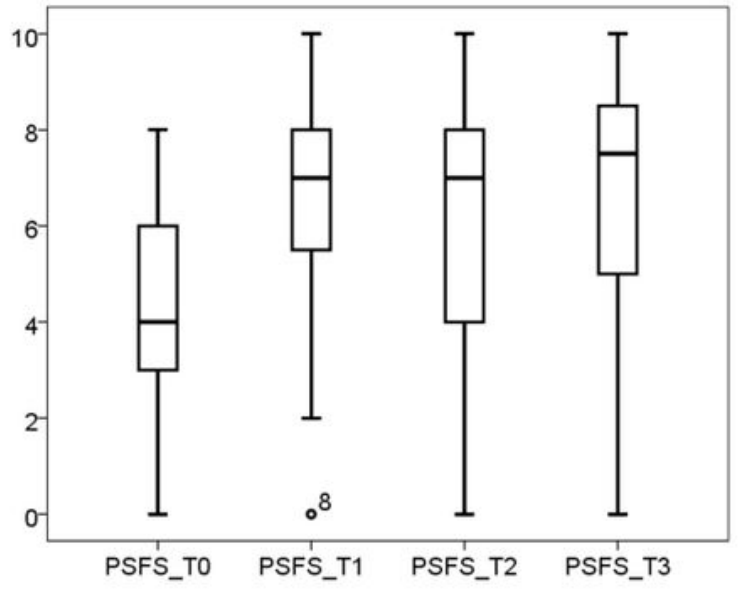

$\mathbf{F}$

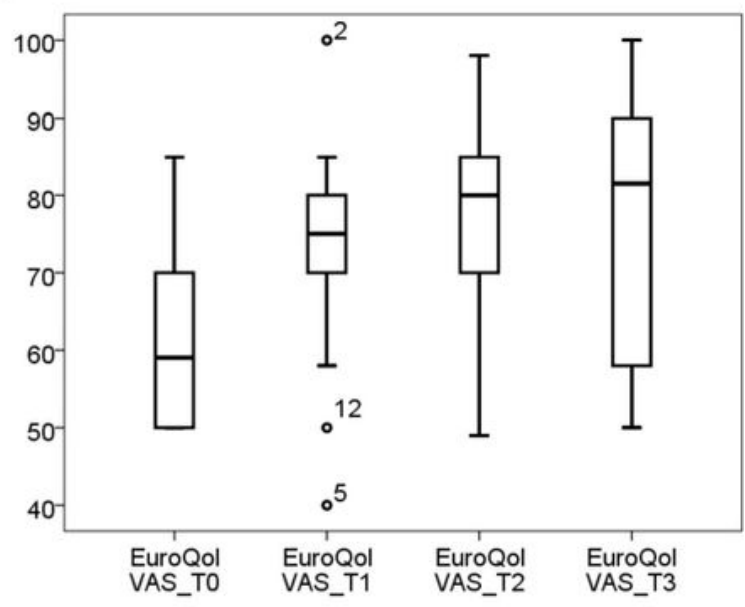

Figure 1

Score distributions / Abbreviations as in Table 1. Raw scores are depicted; TUG values are in seconds (B) 


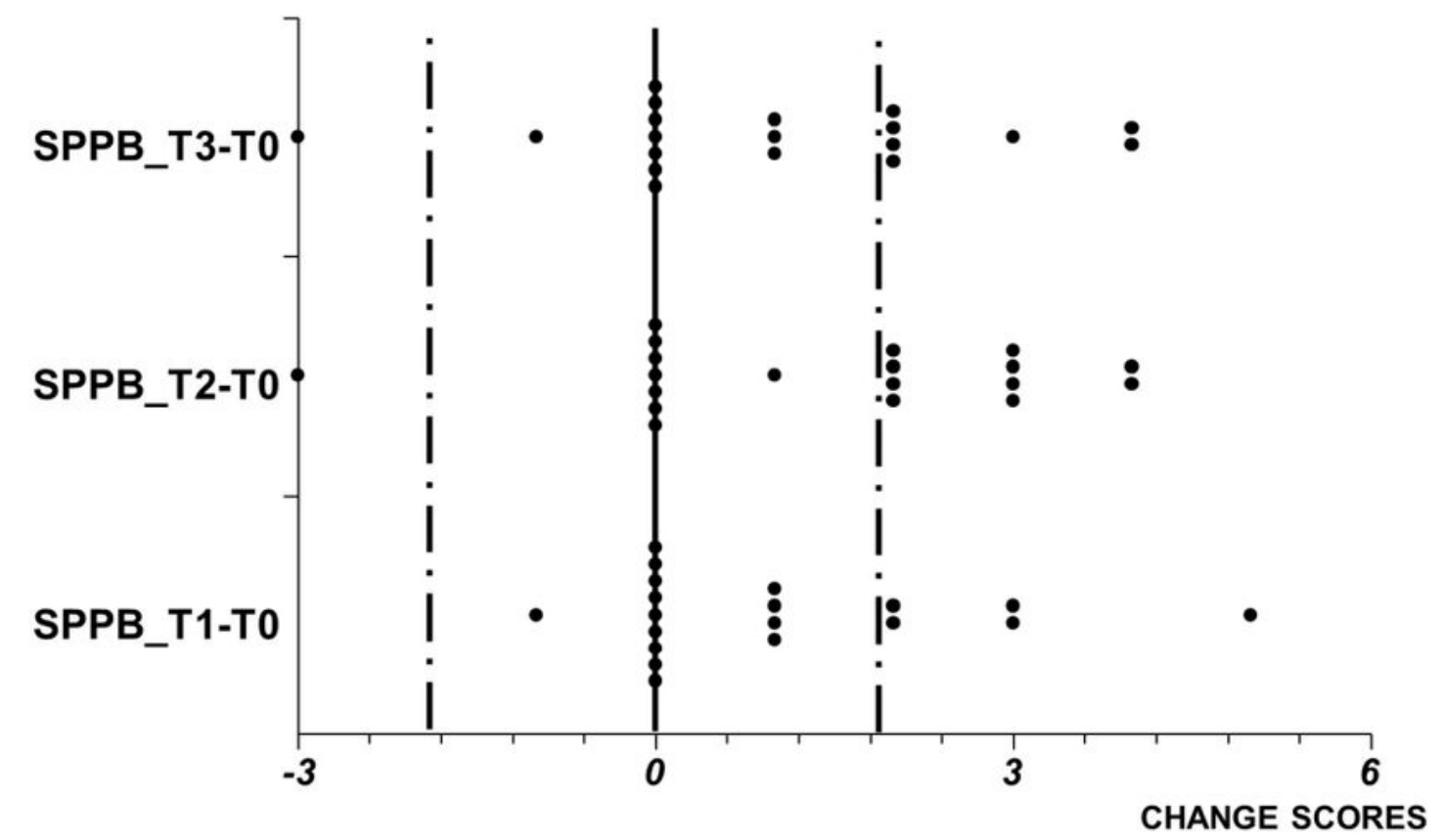

B

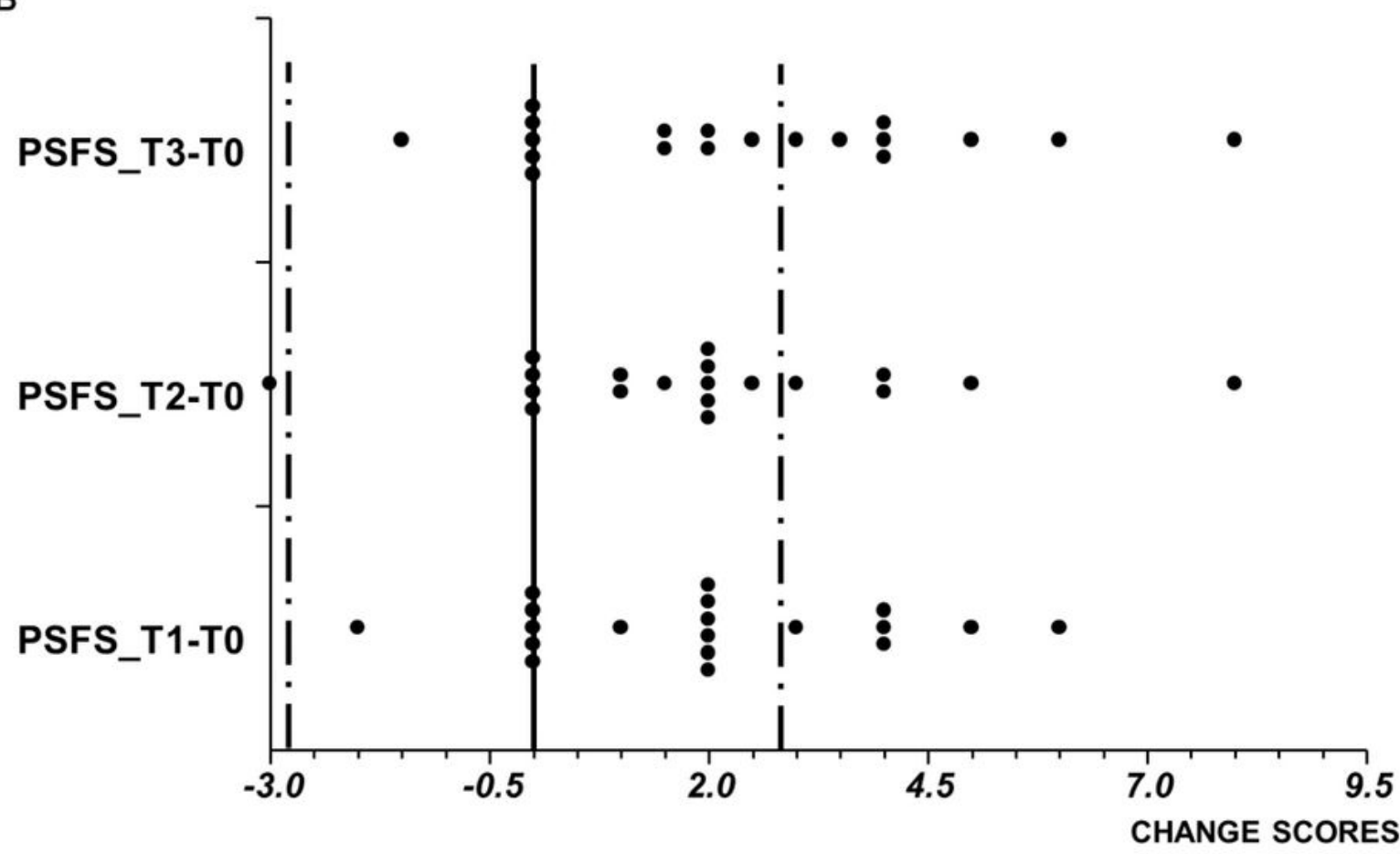

Figure 2

Individual SPPB and PSFS change scores / A dot represents a case, the horizontal lines indicate a difference of 0 and the \pm MDC values. 